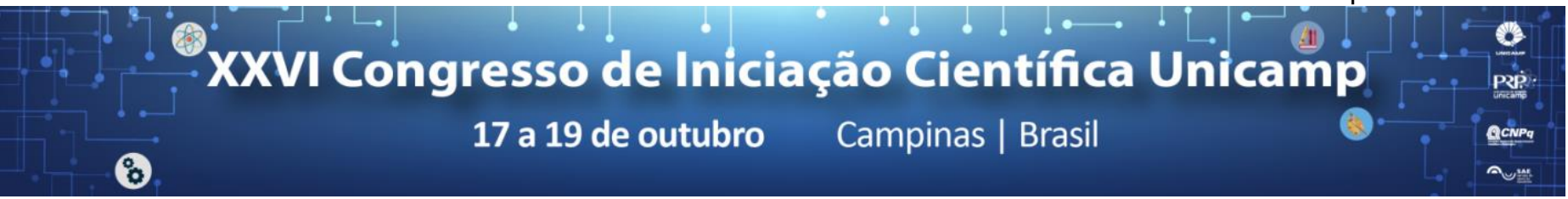

\title{
Monitoramento da microinfiltração coronária nos terços radiculares através do tempo
}

\section{Flávia S. Alves*, Ezequiel Grabrielli, Emely Aveiro, Eloá Cristina B. Pereira, Brenda Paula F. A. Gomes.}

\begin{abstract}
Resumo
A deficiência da restauração coronária influencia diretamente o sucesso do tratamento endodôntico. A microinfiltração coronária ocorre nos casos de perda do material restaurador provisório, fratura ou infiltração pela restauração coronária definitiva e cáries recorrentes, permitindo a contaminação do sistema de canais radiculares que pode atingir os tecidos periapicais. O caminho percorrido pela infiltração coronária atingindo os canais radiculares ainda não foi estudado. Objetivo: Avaliar in vitro, a contaminação nos terços radiculares, após a infiltração pela porção coronária, de dentes tratados endodonticamente. Foram selecionados 62 dentes, os quais foram montados em um aparato para simular a contaminação, que foi realizada com saliva humana de único voluntário. As coletas foram feitas por terços radiculares e os espécimes divididos em 5 grupos experimentais, variando o tempo de contato com a saliva. Foram coletadas amostras de guta-percha dos canais radiculares conforme os terços radiculares e as mesmas foram plaqueadas em FAA (Fastidious Anaerobe Agar) e meio de cultura seletivo M-Enterococcus, sendo analisadas quanto a contagem de unidade formadora de colônia (UFC). Os dados foram tabulados utilizando uma tabela de contingência e analisados estatisticamente através do teste de Kruskal-Willis, com nível de significância de $5 \%(p<0.05)$. Concluímos que os dentes foram progressivamente contaminados de acordo com o tempo, sendo o terço coronário o mais contaminado.
\end{abstract}

Palavras-chave: microinfiltração, endodontia, terços radiculares.

\section{Introdução}

A deficiência da restauração coronária influencia diretamente o sucesso do tratamento endodôntico. Sendo que a microinfiltração coronária ocorre nos casos de perda do material restaurador provisório, fratura ou infiltração pela restauração coronária definitiva, colonizando assim, o sistema de canais radiculares.

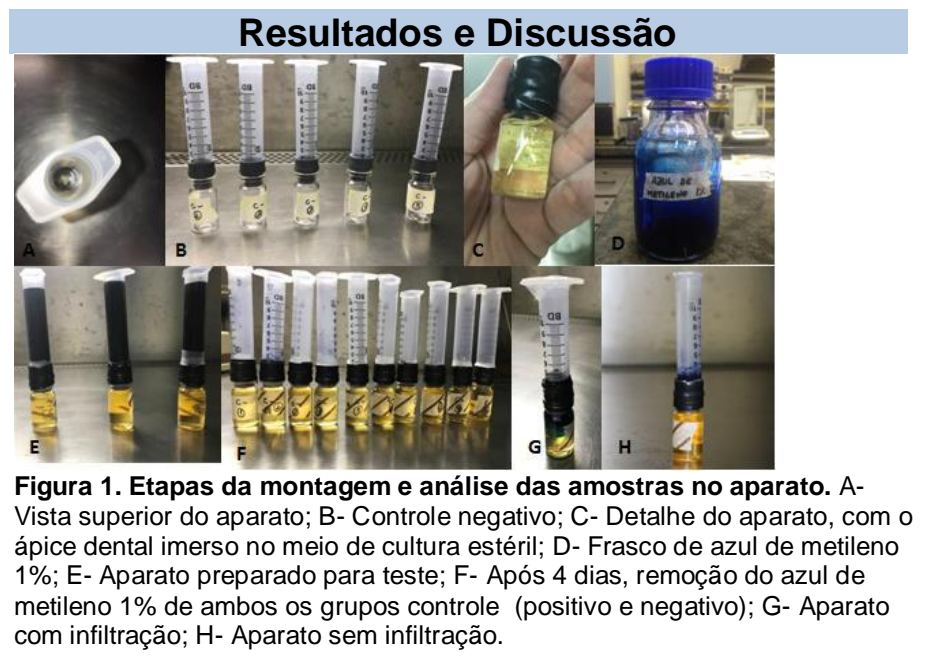

Para o acompanhamento da contaminação microbiana foi realizada a desobturação seriada do canal radicular, coletando individualmente a guta-percha correspondente a cada terço radicular. Esta foi introduzida em meio de cultura e posteriormente plaqueada e incubada para permitir a contagem das unidades formadoras de colônia (UFC/mL).

Os grupos experimentais apresentaram maior contaminação de acordo com o tempo, sendo que o dia 20 apresentou a maior contaminação no terço coronário $(373,20 \pm 209,17)$, terço médio $(281,80 \pm 218,75)$ e no terço apical $(137,40 \pm 125,65)(\mathrm{UFC} / \mu \mathrm{L})$.

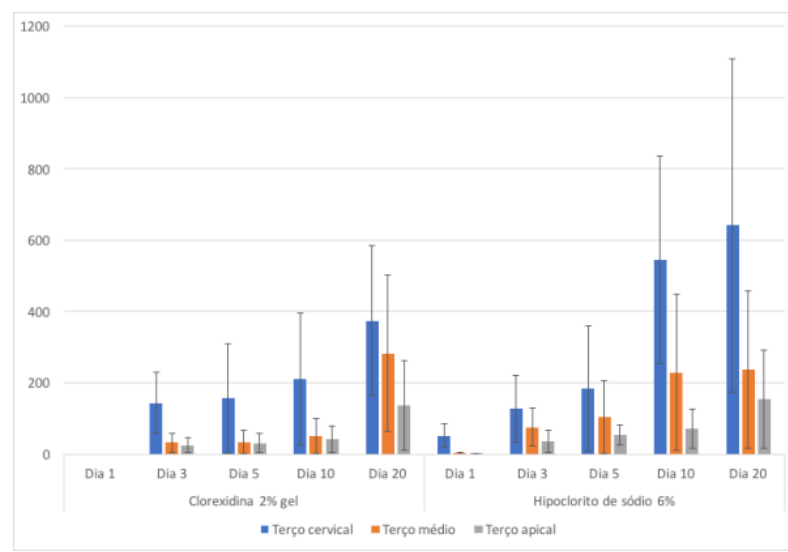

Figura 2. Comparação do nível de contaminação nos terços radiculares, ao longo do tempo, entre os grupos experimentais tratados com clorexidina gel $2 \%$ e hipoclorito de sódio $6 \%$.

$\checkmark$ Foi observado que a infiltração ocorre rapidamente, mesmo na presença de uma obturação eficiente. Esta é capaz de proteger in vitro os canais radiculares da infiltração coronária por um período máximo de 5 dias.

$\checkmark$ Há uma infiltração microbiana maior no terço coronário, seguido pelo médio e apical.

$\checkmark$ Nossos resultados estão de acordo com trabalho de Swanson \& Madison, 1987, que observaram contaminação em um período de 3 dias.

\section{Conclusão}

Concluímos que os dentes foram progressivamente contaminados de acordo com o tempo, sendo o terço coronário o terço radicular mais contaminado.

\section{Agradecimentos}

Este trabalho teve o apoio da FAPESP 2015/23479-5; CNPq 308162/2014-5 \& PIBIC 100453/2018-0 e CAPES.

\footnotetext{
Swanson K.; Madison S. An evaluation of coronal microleakage in endodontically treated teeth. Part I. Time periods. J Endod 1987, 13: 56-9.
} 